\title{
Using FT-NIR Calibration to Determine Soybean Meal Amount in Concentrated Feed Ration Mixtures for Laying Hens
}

\author{
Diren Keskin \\ Vet. Surgeon, Usak, Turkey \\ E-mail: direnkeskin@hotmail.com \\ Ismail Bayram (Corresponding author) \\ Faculty of Veterinary, Afyon Kocatepe University \\ ANS Campus 03100, Afyonkarahisar, Turkey \\ E-mail: ibayram1965@gmail.com
}

The research is financed by BAPK of Afyon Kocatepe University. Project number: 16 SAGBIL.18.

The authors thank to $A K U-B A P K$.

\begin{abstract}
This research was conducted quantitatively to find out the amount of soybean meal used in the concentrate feeds of laying hen by using near infrared spectroscopy (NIR) technique. For this purpose, 30 different concentrated feed ration mixtures of $1 \mathrm{~kg}$ each was prepared for laying hens by increasing the concentration up to $30 \%$. The functional NIR spectra of feed mixtures were obtained at wavelengths of 10000-4000 nm / cm which were evaluated by applying PLS (Partial Least Square) method on the second derivative. In the normalization study, SNV (Standard Normal Variate) method was applied. In addition, data obtained from first order (1st Derivation B Cap 5 Points Gap 2) were prepared for regression. The linear regression method was applied to the normalized spectra by subtracting the Outlier values from the calibration set and in this way the calibration quality parameters were revealed. At this stage, the standard deviations of the $\mathrm{R}^{2}$ value, validation and calibration set were calculated. According to the reflections, the graphs obtained with regression coefficients were taken. In addition, sum of the squares for estimating residual error (V-Set PRESS) of the validation set was also revealed. Outlier values were not part of study because of low calibration quality. In the research, $\mathrm{R}$ value was determined as $0.9947, \mathrm{R}^{2}$ value, 0.9894 and standard deviation value as 0.6762 of calibration set. Moreover, $\mathrm{R}$ value was determined as $0.9919, \mathrm{R}^{2}$ value, 0.9839 and standard deviation value as 0.8398 of validation set and the principal component value (Principal Components) were found to be around 14. The regression consistency was between 80-110 and it was obtained by dividing standard error value (SEC) of calibration to standard error of estimation (SEP). In conclusion it is evident from the results that method of FT-NIR spectroscopy is a reliable way to determine the extent at which the soybean meal is quantitatively used in laying hen feed mixtures.
\end{abstract}

Keywords: Soybean meal, FT-NIR, Quantitative amounts, Calibration.

DOI: $10.7176 / \mathrm{JSTR} / 5-9-03$

\section{Introduction}

In the feed factories, it is not possible to determine precisely the amount of feedstuffs entering to the mixture according to the ration content or the feedstuffs added to the mixture content. This situation is inadequate to determine the quality of mixed feeds. The quality of the concentrate feed produced according to certain ration formulations varies according to the feed law and whether the feed content meets the animal needs rather than the type of feedstuffs entering the mix. Therefore, rather than determining feed content, studies are carried out in the form of adulterated product screening in feed mixtures using NIR techniques. Fourier transform near-infrared spectroscopy (FT-NIR) is a non-

17 | P a g e

www.iiste.org 
destructive and rapid technique that can reliably analyze organic matter. This analytical method had a major impact on the food industry and agriculture. According to Williams (2001), numerous analytical methodologies based on near infrared spectroscopy have shown that this technique can safely and quickly cope with a wide range of analyzes, such as determining proteins, dry matter, carbohydrates, and fat content in different food types. Determination of moisture, protein, fat and carbohydrate contents by wet methods is a laborious process that requires time and characteristically produces a lot of chemical waste. However, methods using the FT-NIR technique provide precise and rapid results in order to be an alternative to such determinations with minimal or blank sample preparation and no waste (Kandalave et al., 2012; SalgóveGergely, 2012; Zhou et al., 2012). However, multivariate calibration methods should be used to obtain quantitative information for the simultaneous evaluation of spectral properties and various parameters in the NIR region. Multivariate calibration methods are part of chemometries that require a large number of analytical experiments to develop a mathematical model. Furthermore, once a model is constructed, it should be validated by a data group that is not part of the calibration (Agelet and Hurburgh, 2010). Near infrared spectroscopy is a rapid technique that can be used for the simultaneous detection and analysis of multiple components (Baianu et al., 2012; Louw and Theron, 2010). The different chemical components in the samples can be measured rapidly by utilizing the vibrational absorption modes of compounds in the near infrared region of the spectrum and using near infrared reflection spectroscopy (Martelovidal and Vazquez, 2014). The frequency folds of the moisture, protein, fat and carbohydrate of the various hydrogen-containing groups and the combination bands are all located in the near infrared reflection region, and the characteristic vibration information of the hydrogencontaining groups in these organic molecules can be used to determine the composition of the mixtures that make up the substance (De-Boever et al. 1995). Zhu et al. (2011) analyzed soybean seeds using the NIR device. In a study, the NIR method was used to determine moisture, protein, fat, carbonate and carbohydrate concentration of soybean from Brazil. Spectra in the range of $4000-10,000 \mathrm{~cm}-1$ were obtained in the study. In the research, PLS (Partiel least Square) and SNV (Standard Normal Variate) methods were used as statistical models. The best calibration models found in this study were those used to determine protein and moisture content, and $\mathrm{R}^{2}=0.81$ and $\mathrm{R}^{2}=0.80$, respectively. This result demonstrates the feasibility of using NIR technique in soybean quality determination (Ferreira et al., 2013). The calibrations obtained after measurements with NIR in soybeans were mainly developed with soybean powder samples (Sato et al., 1994; Myoung et al., 2001). In addition to protein and fat measurements, which are the main nutrient components of soybeans, it is aimed to measure the subunits of these amino acids and fatty acids by means of NIR. Crude protein and protein fractions of soybean were analyzed by NIR (Cho et al., 1987; Pazdernik et al., 1996). Soybean oil was quantitatively determined on the NIR device using the least squares (PLS) method (Parreira et al., 2002). A method has been developed to determine the total phospholipid content in soybean oil by FT-NIR spectroscopy (Nzai et al., 1998). Analysis of the amino and fatty acid composition in soybean seed by NIR has also been reported with moderately high correlation coefficients between NIR values and reference values (Pazdernik et al. 1996). Although similar NIR studies have not been found to quantitatively determine the amount of soybean meal in concentrated feeds, adulteration studies in crab meat with similar study have been reported. In the study, PLS and PCR analyzes were performed as regression analysis on NIR device in order to estimate adulteration in crab meat. The accuracy of the estimation models was examined in terms of low standard calibration error (SEC), low standard estimation error (SEP) and high correlation coefficient $\left(\mathrm{R}^{2}\right)$. In the study, the standard error of calibration was found to be $0.251, \mathrm{R}^{2}$ : 0.997 , estimation standard error: 0.252 , and $\mathrm{R}^{2}$ value was 0.997 . The results show that NIR technology can be used successfully to detect adulteration in crab meat samples prepared with imitation crab meat (Gayo et al. 2006).

In the light of this information, this study was carried out with the aim of establishing NIR calibration to determine the percentage of soybean meal which is one of the most used feedstuffs as protein source for laying hens.

\section{Material and Method}

In this study, 30 commercial laying hen rations were prepared with the same nutrient values; isocaloric and isonitrogenic. Each ration was prepared as $1 \mathrm{~kg}$ and nutritional values of diets were regulated according to NRC (2005) norms. In the 30 feed mixtures samples prepared, soybean meal at $1 \%$ level was used in the number one ration, and then soybean meal was increased by $1 \%$ in each ration content up to $30 \%$ in the last ration. Before the feed mixtures were formed, each feed feedstuffs purchased from a private feed factory was ground with an ultra-centrifugal rotor grinder (ZM200, Retsch Ltd., Düsseldorf, Germany) at the feed lab. The $1 \mathrm{~kg}$ feed mixture prepared in accordance with the ration formulations was kept in FT-NIR device until the rations were read and then in airtight nylon bags.

18 | P a g e 
Immediately after the feed mixtures were prepared, each feed mixture was placed in a glass petri dish and each sample was placed on the automatic retort of the NIR device (NIRMaster ${ }^{\circledR}$, BüchiLabortechnik AG, Flawil, Switzerland) and spectra were collected from each sample by spectra 6 times. The collected spectra were stored electronically in a suitable format with the program of the same name provided by the manufacturer on the desktop computer integrated into the FT-NIR device. The feedstuffs used in the study were obtained from a private commercial feed factory. Ration formulations used in feed mixtures are given in Table 1 and Table 2.

Table 1. Ration ingredients (1-15\% Soybean Meal)

\begin{tabular}{|l|c|c|c|c|c|c|c|c|c|c|c|c|c|c|c|}
\hline \multicolumn{1}{|c|}{ Feedstuffs } & $\mathbf{\% 1}$ & $\mathbf{\% 2}$ & $\mathbf{\% 3}$ & $\mathbf{\% 4}$ & $\mathbf{\% 5}$ & $\mathbf{\% 6}$ & $\mathbf{\% 7}$ & $\mathbf{\% 8}$ & $\mathbf{\% 9}$ & $\mathbf{\% 1 0}$ & $\mathbf{\% 1 \mathbf { l }}$ & $\mathbf{\% 1 2}$ & $\mathbf{\% 1 3}$ & $\mathbf{\% 1 4}$ & $\mathbf{\% 1 5}$ \\
\hline Barley & 5,44 & 5,94 & 6,03 & 6,03 & 6,03 & 6,03 & 6,38 & 6,38 & 6,48 & 6,58 & 6,78 & 7,13 & 7,23 & 7,63 & 7,63 \\
\hline Vegetable oil & 6,00 & 5,80 & 5,80 & 5,80 & 5,60 & 5,60 & 5,40 & 5,40 & 5,40 & 5,40 & 5,40 & 5,30 & 5,30 & 5,10 & 5,10 \\
\hline Wheat grain & 2,00 & 2,00 & 2,10 & 2,30 & 3,00 & 3,10 & 3,60 & 3,60 & 3,60 & 3,70 & 3,70 & 3,80 & 3,80 & 4,00 & 4,00 \\
\hline Corn grain & 39,00 & 39,00 & 39,00 & 39,00 & 39,00 & 39,00 & 39,00 & 39,00 & 39,00 & 39,00 & 39,00 & 39,00 & 39,00 & 39,00 & 39,00 \\
\hline Sunflower meal,36\% CP & 24,49 & 23,39 & 22,70 & 21,80 & 20,50 & 19,80 & 18,50 & 18,00 & 17,50 & 16,70 & 16,00 & 15,20 & 14,60 & 13,60 & 13,00 \\
\hline Sunflower mea1,23\% CP & 2,00 & 2,00 & 2,00 & 2,00 & 2,00 & 2,00 & 2,00 & 2,00 & 2,00 & 2,00 & 2,00 & 2,00 & 2,00 & 2,00 & 2,00 \\
\hline Corn gluten,43\% CP & 8,40 & 8,20 & 7,70 & 7,40 & 7,20 & 6,80 & 6,50 & 6,00 & 5,40 & 5,00 & 4,50 & 4,00 & 3,50 & 3,10 & 2,70 \\
\hline Soybean meal,44\% CP & 1,00 & 2,00 & 3,00 & 4,00 & 5,00 & 6,00 & 7,00 & 8,00 & 9,00 & 10,00 & 11,00 & 12,00 & 13,00 & 14,00 & 15,00 \\
\hline Dicalcium phosphate & 1,75 & 1,75 & 1,75 & 1,75 & 1,75 & 1,75 & 1,70 & 1,70 & 1,70 & 1,70 & 1,70 & 1,65 & 1,65 & 1,65 & 1,65 \\
\hline Limestone & 9,17 & 9,17 & 9,17 & 9,17 & 9,17 & 9,17 & 9,17 & 9,17 & 9,17 & 9,17 & 9,17 & 9,17 & 9,17 & 9,17 & 9,17 \\
\hline Salt & 0,40 & 0,40 & 0,40 & 0,40 & 0,40 & 0,40 & 0,40 & 0,40 & 0,40 & 0,40 & 0,40 & 0,40 & 0,40 & 0,40 & 0,40 \\
\hline Vitamin-Mineral Mix & 0,35 & 0,35 & 0,35 & 0,35 & 0,35 & 0,35 & 0,35 & 0,35 & 0,35 & 0,35 & 0,35 & 0,35 & 0,35 & 0,35 & 0,35 \\
\hline Crude Protein,\% & 17,7 & 17,7 & 17,7 & 17,7 & 17,7 & 17,7 & 17,7 & 17,7 & 17,7 & 17,7 & 17,7 & 17,7 & 17,7 & 17,7 & 17,7 \\
\hline Metabolisable energy,Kcal/kg & 2745 & 2739 & 2741 & 2746 & 2744 & 2746 & 2745 & 2744 & 2743 & 2747 & 2748 & 2746 & 2747 & 2739 & 2740 \\
\hline Calcium,\% & 3,99 & 3,99 & 3,99 & 3,99 & 3,99 & 3,99 & 3,98 & 3,98 & 3,98 & 3,98 & 3,98 & 3,97 & 3,97 & 3,97 & 3,97 \\
\hline Phosphorus,\% & 0,38 & 0,38 & 0,38 & 0,38 & 0,38 & 0,39 & 0,38 & 0,38 & 0,38 & 0,38 & 0,38 & 0,38 & 0,38 & 0,38 & 0,38 \\
\hline
\end{tabular}

Table 2. Ration ingredients (15-30\% Soybean Meal)

\begin{tabular}{|c|c|c|c|c|c|c|c|c|c|c|c|c|c|c|c|}
\hline Feeds & $\% 16$ & $\% 17$ & $\% 18$ & $\% 19$ & $\% 20$ & $\% 21$ & $\% 22$ & \%23 & $\% 24$ & $\% 25$ & $\% 26$ & $\% 27$ & $\% 28$ & $\% 29$ & $\% 30$ \\
\hline & & & 8,58 & 8,58 & 8,68 & &, 18 & 9,73 & 0,23 & 10,83 & 1,23 & 11,83 & 13,58 & 2,58 & 1,58 \\
\hline & 10 & 5,10 & 5,00 & 5,00 & 5,00 & 4,80 & 4,80 & 4,60 & 4,40 & 4,20 & 4,10 & 4,00 & 3,60 & 3,60 & 3,60 \\
\hline & & 4,00 & 4,00 & 4,20 & 4,20 & 4,40 & 4,40 & 4,40 & 4,40 & 4,40 & 4,40 & 4,40 & 4,40 & 4,40 & 4,40 \\
\hline & 39,00 & 39,00 & 39,00 & 39,00 & 39,00 & 39,00 & 39,00 & 39,00 & 39,00 & 39,00 & 39,00 & 39,00 & 39,00 & 39,00 & 39,00 \\
\hline Sunflo & 12,30 & 11,60 & 10,60 & 9,70 & 9,00 & 8,40 & 7,10 & 5,80 & 4,50 & 3,10 & 1,80 & 0,30 & 0,00 & 0,00 & 0,00 \\
\hline 年 & 00 & 2,00 & 2,00 & 2,00 & 2,00 & 2,00 & 2,00 & 2,00 & 2,00 & 2,00 & 2,00 & 2,00 & 0,00 & 0,00 & 0,00 \\
\hline (190 & 2,20 & 1,80 & 1,30 & 1,00 & 0,60 & 0,10 & 0,00 & 0,00 & 0,00 & 0,00 & 0,00 & 0,00 & 0,00 & 0,00 & 0,00 \\
\hline , soyoedint & 16,00 & 17,00 & 18,00 & 19,00 & 20,00 & 21,00 & 22,00 & 23,00 & 24,00 & 25,00 & 26,00 & 27,00 & 28,00 & 29,00 & 30,00 \\
\hline Dicalcium & 1,65 & 1,65 & 1,60 & 1,60 & 1,60 & 1,60 & 1,60 & 1,55 & 1,55 & 1,55 & 1,55 & 1,55 & 1,50 & 1,50 & 1,50 \\
\hline Timponon & 9,17 & 9,17 & 9,17 & 9,17 & 9,17 & 9,17 & 9,17 & 9,17 & 9,17 & 9,17 & 9,17 & 9,17 & 9,17 & 9,17 & 9,17 \\
\hline Salt & 0,40 & 0,40 & 0,40 & 0,40 & 0,40 & 0,40 & 0,40 & 0,40 & 0,40 & 0,40 & 0,40 & 0,40 & 0,40 & 0,40 & 0,40 \\
\hline 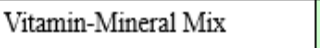 & 0,35 & 0,35 & 0,35 & 0,35 & 0,35 & 0,35 & 0,35 & 0,35 & 0,35 & 0,35 & 0,35 & 0,35 & 0,35 & 0,35 & 0,35 \\
\hline & 17,7 & 17,7 & 17,7 & 17,7 & 17,7 & 17,7 & 17,7 & 17,7 & 17,7 & 17,7 & 17,7 & 17,7 & 17,7 & 18,1 & 18,4 \\
\hline Metabolisable energy, $\mathrm{Kcal} / \mathrm{kg}$ & 2742 & 2744 & 2744 & 2749 & 2751 & 2739 & 2749 & 2747 & 2744 & 2742 & 2746 & 2751 & 2750 & 2746 & 2742 \\
\hline dilcuin, $\%$ & 3,97 & 3,98 & 3,96 & 3,96 & 3,97 & 3,97 & 3,97 & 3,95 & 3,96 & 3,96 & 3,96 & 3,96 & 3,94 & 3,94 & 3,94 \\
\hline Phosphorus,\% & 0,38 & 0,38 & 0,38 & 0,38 & 0,38 & 0,38 & 0,38 & 0,38 & 0,38 & 0,38 & 0,38 & 0,38 & 0,38 & 0,38 & 0,38 \\
\hline
\end{tabular}




\subsection{Creation of Calibrations and Data Analysis}

Calibrations and statistical evaluations based on obtained spectra were evaluated with NIRCAL program (BüchiLabortechnik AG, Flawil, Switzerland). Within the spectra itself, calibration and validation sets are separated by the program. The spectra obtained were evaluated by PLS (Partial Least Square) method on the secondary derivative (second derivative). Outlier values were subtracted from calibration set and linear regression was applied to normalized spectra and calibration quality parameters were determined. At this stage $\mathrm{R}^{2}$ value, standard deviations of validation and calibration set were calculated. Graphical outputs obtained by regression coefficients were obtained according to reflectances. In addition, the squares sum (V-Set PRESS) of the estimation of the validation set was obtained. Outlier values were determined by the program and were not included in the study due to the decrease in calibration quality.

\section{Results}

The reflectance views $(1 / \log )$ and normalized spectra as a result of the preliminary applications applied to the spectra are shown in Graph 1.

\section{Pretreated Spectra}

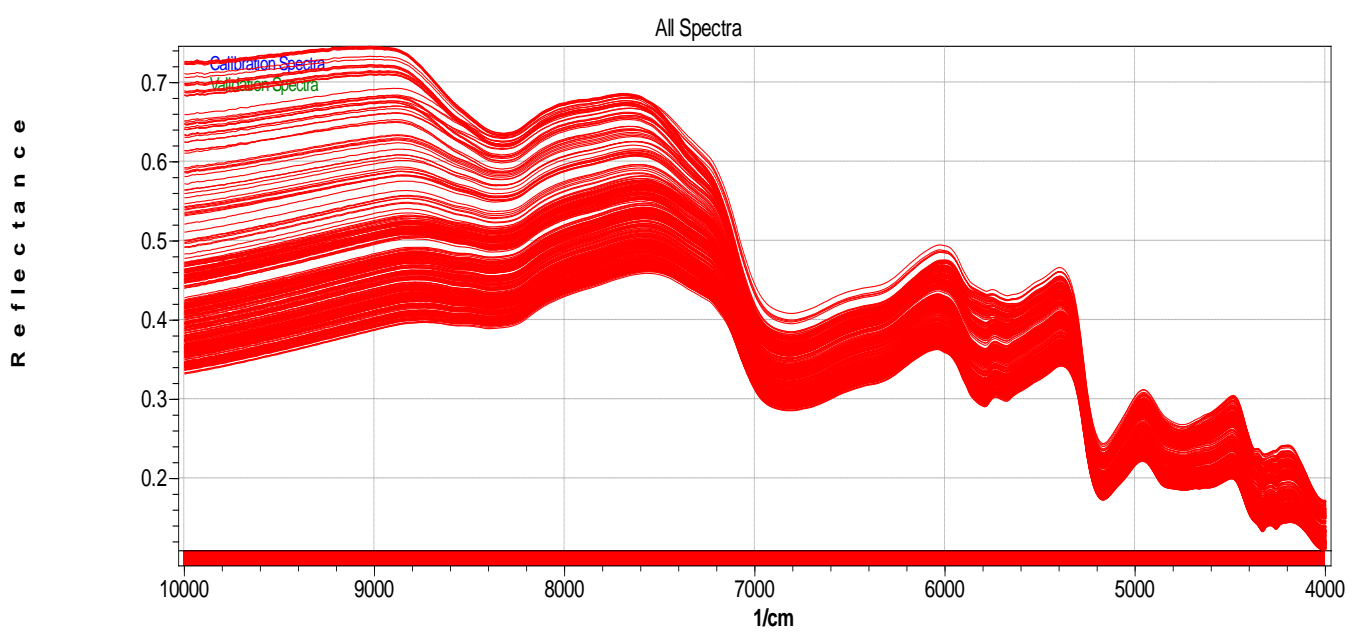

Graph 1. Spectra Set with Normalization Applied.

Functional spectra obtained after application were obtained at wavelengths of $10000-4000 \mathrm{~nm} / \mathrm{cm}$. The estimated residual error of the validation set was obtained by using the V-Set PRESS (Principal Components) 14. Basic component values via V-Set PRESS are shown in Graph 2.

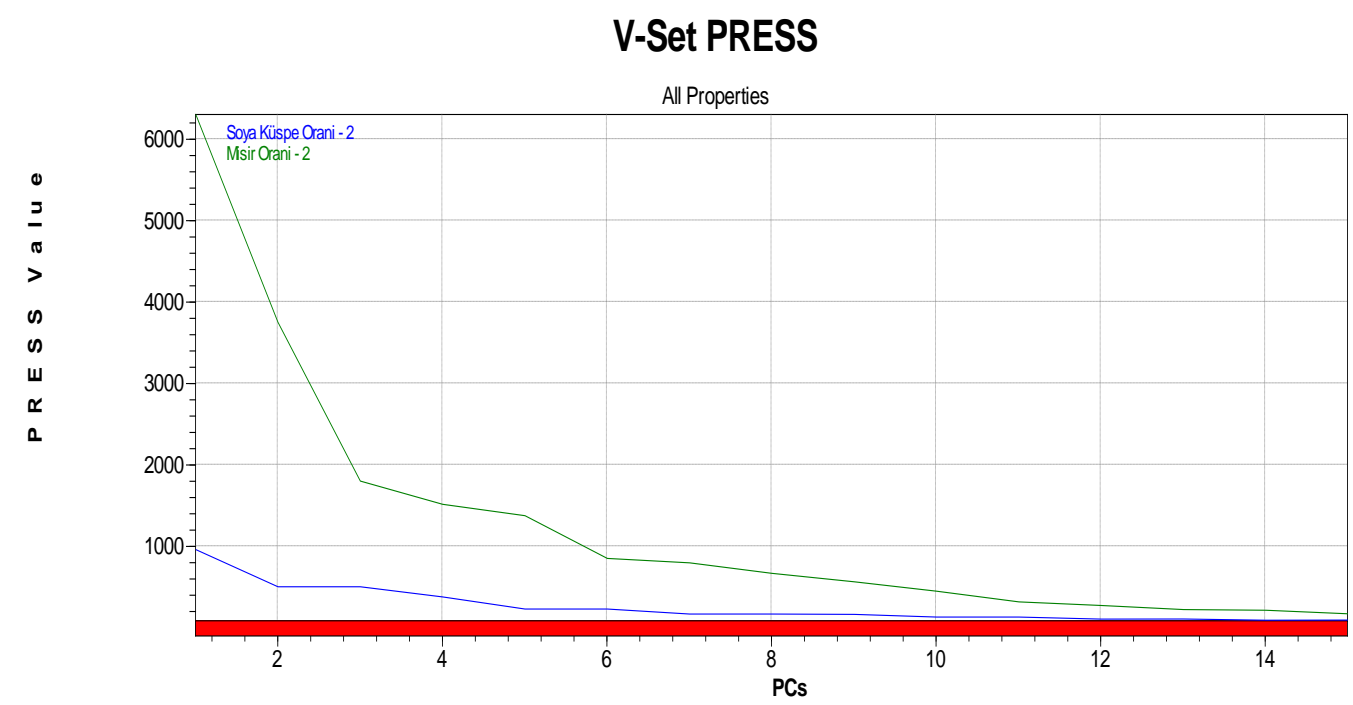

Graph 2. Estimation The sum of squares of residual error. 
The obtained regression consistency was obtained by dividing the standard error value (SEC) of the calibration by the estimation standard error (SEP). Consistency value was determined between 80 and 110. The results of the consistency analysis are shown in Graph 3.

\section{Consistency}

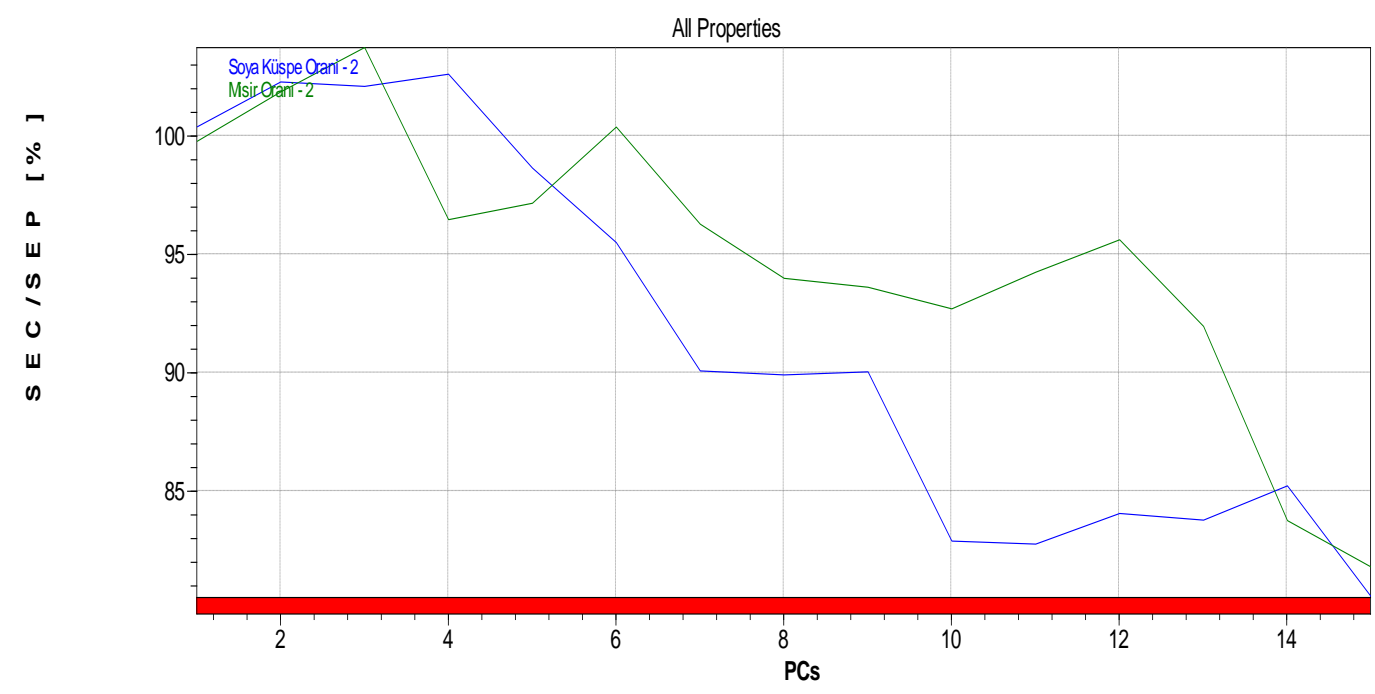

Graph 3. Consistency Analysis of Calibration Set.

The output of the linear regression values obtained from the calibration and validation sets is shown in Graph 4.

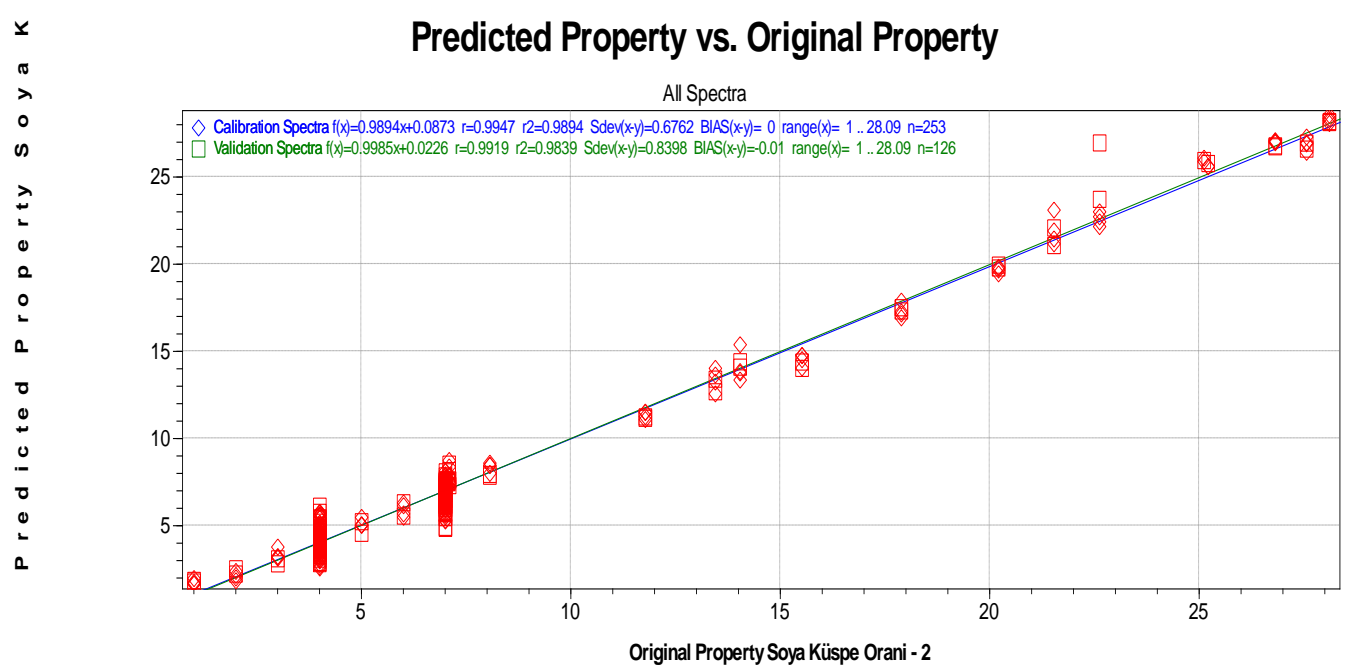

Graph 4. Calibration and Validation Set Models

For the regression analysis, 253 of the calibration set; 126 measurements were included in validation sets. As a result of the analysis, the model of calibration and validation sets was formed as follows:

\section{Calibration set:}

- $f(x)=0.9894 x+0.0873$

- $\mathrm{R}=0.9947$

- $\mathrm{R}^{2}=0.9894$ 
- $\quad$ Standart deviation $=0.6762$

- $\quad \mathrm{BIAS}=0$

\section{Validation set:}

- $f(x)=0.9985 x+0.0226$

- $\mathrm{R}=0.9919$

- $\mathrm{R}^{2}=0.9839$

- $\quad$ Standart deviation $=0.8398$

- $\quad$ BIAS $=0.01$

\section{Discussion}

In this study, the main component of the study was soybean meal, which is the most commonly involved in poultry diets, especially layer hens and broilers. For this purpose, it is aimed to determine the amount of soybean meal that is mixed in 30 different layer hen diets by using NIR device. In the present study, the feedstuffs were obtained from a private feed factory. Subsequently, feedstuffs were ground separately in the lab. Then, 30 different feed mixes, each of which increased by $1 \%$ of the soybean meal, were prepared to have a total mix weight of one $\mathrm{kg}$. One $\mathrm{kg}$ of dietary ration mixtures were started by using $1 \%$ of soybean meal in the first ration, then soybean meal was increased by $1 \%$ in other mixtures and $1 \%$ - $30 \%$ soybean meal was used. Then, 30 different feed ration mixtures were read 3 times in NIR device and 180 spectra were collected.

In FT-NIR calibration studies, determination coefficient value $\left(\mathrm{R}^{2}\right)$ was used to calculate the estimation value. $R^{2}$, which is the determination coefficient value, is calculated as the square of the $R$ value. This calculated value is shown as the regression coefficient, which is the $t$ determination of the relationship between the variables (Sohn et al., 2006). The determination coefficient value $\left(\mathrm{R}^{2}\right)$ is between zero $(0)$ and one (1) number. The $\mathrm{R}^{2}$ value is considered to be such a strong result in the extent of its proximity to an integer number. In other words, this shows the reliability of the obtained calibration (Sohn et al., 2006). In the present study, the spectra set obtained as follows; $R$ value was $0.9947, R^{2}$ value was 0.9894 and standard deviation value was 0.6762 . Altough, no previous FT-NIR calibration studies have been performed, showing exactly the proportion of soybean added to the feed mixes, there was performed a similar study about FT-NIR calibration of corn grain (Yildirim and Bayram,2019). This can also be demonstrated by mixing tests to ensure the confidence of the producers preparing the mixed feeds from the preparation of rations in feed mills to the final stage of production. Furthermore, the point reached in feed technology is extremely high, in other words, it may be due to the fact that feed producing factories rely on their feed formulations and mixing ratios to be successful and technological equipment. The problem here is that feed producers declare the feedstuffs in the feeds produced by using the legal deficiencies and gaps that they produce for sale unrealistic and this situation cannot be determined by the authorities. Although not the same content, there are a large number of quantitative studies conducted on the same logic in the determination of feed or food adulterations intended to deceive consumers in animal feeds or human foodstuffs. $\mathrm{Rcv}^{2}$ value was found in the range of $0.99-0.98$ in an adulteration study conducted for quantitative determination of soy flour in processed meat products. In this study, it has been shown that adulterations can be detected in salami and sausages which are processed meat products. In another quantitative study related to the subject, mixtures of sunflower, canola and hazelnut oils added to sesame oil for adulteration purposes could be determined quantitatively by FT-NIR device. $\mathrm{R}^{2}$ value in the study of canola oil; sunflower oil was found to be $0.9618,0.9344$ and hazelnut oil was found to be 0.9633. It is shown that the methods used in quantitative studies in meat products and sesame oil given examples are in harmony with the methods in our study and that the editing is correct. Similarly, in another quantitative study on honey, it has been reported that the amount of sugar mixed into honey in different proportions can be quantitatively determined by FT-NIR method. In the same study, functional spectra were found to be $8000-40004 / \mathrm{cm}$ wavelengths. This result is similar to the functional spectra of $10000-4000 \mathrm{~mm} / \mathrm{cm}$. The regression consistency value obtained in the present study was obtained by dividing the standard eror value (SEC) of the calibration by the estimation standard eror value (SEP). The consistency value found in the study was determined between $80-110$ values. In a quantitative study of the subject using the PLS method in honey sample (Gonzalez et al. 2018), an estimation was made including a pure product consisting only of honey as well as another product added to the honey. The estimated values obtained for the sample set used in the study were $0.69 \%$ for $0 \%, 5.27 \%$ for $5 \%, 14.85 \%$ for $15 \%, 24.31 \%$ for $25 \%$ and $42.63 \%$ for $45 \%$, respectively. This result proved that quantitative 
identification model for honey sample works. In another study conducted using the PLS method with FTNIR (Cuibus et al., 2014), palm fat was added to the cheese in different amounts for adulteration, and its consistency value (mean recovery rate) was 108 and $\mathrm{R}^{2}$ value was found to be 0.9695 . In this study, the actual and predicted values of palm fat added to cheese in different proportions were as follows; $4 \%$ for $5 \%, 10.1 \%$ for $10 \%, 20.2 \%$ for $15 \%, 24.2 \%$ for $20 \%$ and $41.6 \%$ for $40 \%$. Furthermore, in this study, the regression consistency value was determined between $80-110$ values. This result shows that this method, which we use quantitatively to determine the amount of soybean meal in layer hen feeds, is largely accurate.

\section{Conclusion}

This is a preliminary study of the use of FT-NIR method to estimate the amount of soybean meal in the feed, which is added to layer hen concentrate feeds at different levels from $1 \%$ to $30 \%$. The high level of validation $R^{2}: 0.9839$ obtained in the study confirms that FT-NIR spectroscopy method can quantitatively detect soybean meal in laying hen concantrated feed. The amount of soybean meal in laying hen concentrated feeds could be determined quantitatively $99 \%$ accurately by FT-NIR technique. In addition, a high correlation coefficient was determined in the regression analysis using PLS method. Moreover, $44 \%$ crude protein content of soybean meal which was added to the layer hen feeds at levels of $1 \%$ to $30 \%$ could be determined accurately by FT-NIR spectroscopy technique. This suggests that it is possible to calibrate with FT-NIR technique to estimate the amount of soybean meal in laying hen feeds. As a result, it is concluded that the estimation level may be higher by adding the soybean meal levels to $0.5 \%$ or less intervals instead of $1 \%$ in order to quantitatively determine the level of soybean meal in concentrated feeds.

\section{References}

Agelet, L. E., Hurburgh, C. R. (2010). A tutorial on near infrared spectroscopy and its calibration. Critical Reviews in Analytical Chemistry, 40(4), 246-260.

Baianu, I. C., You, T., Costescu, D. M., Lozano, P. R., Prisecaru, V.I., Nelson, R. L. (2012). Determination of soybean oil, protein and amino acid residues in soybean seeds by high resolution nuclear magnetic resonance (NMRS) and near infrared (NIRS). Nature Precedings. http://dx.doi.org/10.1038/npre.2012.7053.1Date of access:2019.

Cho, R.K., Iwamoto, M., Saio, K. (1987). Determination of 7S and 11S Globulins in GroundWhole Soybeans by Near Infrared Reflectance Spectroscopy Analysis. Nippon Shokuhin KogyoGakkaishi. 34(10), 666-672.

Cuibus,L., Maggio,R., Mureșan,V., Diaconeasa,Z., Fetea,F., Socaciu,C. (2014) Preliminary Discrimination of Cheese Adulteration by FT-IR Spectroscopy Bulletin UASVM Food Science and Technology 71(2).

De Boever, J.L., Cottyn, B.G., Vanacker, J.M., Boucqué, C.V. (1995). Theuse of NIRS to predict the chemical composition and the energy value of compound feeds for cattle. Anim. FeedSci. Technol. $51,243-253$.

Ferreira,D.S., Pallone,J.A.L., Poppi,R.J. (2013).Fourier transform near-infrared spectroscopy (FTNIRS) application to estimate Brazilian soybean [Glycinemax (L.) Merril] composition Food Research International 51,53-58.

Ferreiro-González,M., Espada-Bellido,E., Guillén-Cueto,L., Palma,M., Barroso,C.G., Gerardo F. Barbero,G.F. (2018). Rapid quantification of honey adulteration by visible-near infrared spectroscopy combined with chemometrics. Talanta, 188: 288-292.

Gayo,J., Hale,S.A., Blanchard,S.M. (2006). Quantitative Analysis and Detection of Adulteration in Crab Meat Using Visible and Near-Infrared Spectroscopy J. Agric. Food Chem. 54, 1130-1136. 
Kandala, C. V., Sundaram, J., Puppala, N. (2012). Analysis of moisture content, total oil and fatty acid composition by NIR reflectance spectroscopy: A review. Lecture Notes in Electrical Engineering, 146, 59-80.

Louw, E. D., Theron, K. I. (2010). Robust prediction models for quality parameters in Japanese plums (PrunussalicinaL.) using NIR spectroscopy. Postharvest Biology and Technology.,58, 176-184. https://doi.org/10.1016/j.postharvbio.2010.07.001.

Martelovidal, M. J., Vazquez, M. (2014). Evaluation of ultraviolet, visible, and near infrared spectroscopy for the analysis of wine compounds. Czech Journal of Food Sciences, 32, 37-47.

Myoung, G.C., In, Y.B., Sung, T.K., Won, Y.H., Doo, C.S., Huhn, P.M., Kwang, H.K. (2001).Nondestructive method for selection of soybean lines contained high protein and oil by near infrared reflectance spectroscopy. Korean J Crop Sci 46(5), 401-406.

National Research Council. (2001). Nutrient Requirements for laying hen. Seventh Revised Edition. National Academy of Science, Washington, D.C.

Nzai, J. M.,Proctor, A. (1998). Determination of phospholipids in vegetable oil by Fouriertransform infrared spectroscopy. J. Am. Oil Chem. Soc. 75(10), 1281-1289.

Parreira, T.F., Ferreira, M.C., Sales, H.J.,Dealmeida, W.B. (2002). Quantitative determinationof epoxidized soybean oil using near-infrared spectroscopy and multivariate calibration. Appl.Spectrosc. 56(12), 1607-1614.

Pazdernik, D.L., Plehn, S.J., Halgerson, J.L., Orf, J.H.(1996). Effect of Temperature and Genotype on the Crude Glycinin Fraction (11S) of Soybean and Its Analysis by Near-Infrared Reflectance Spectroscopy (Near-IRS). J. Agric. Food Chem. 44 (8), 2278-2281.

Salgó, A., Gergely, S. (2012). Analysis of wheat grain development using NIR spectroscopy. Journal of Cereal Science, 56(1), 31-38.

Sato, T, Abe, H., Kawano, A., Ueno, G., Suzuki, K. Iwamoto, M. (1994). Near-Infrared Spectroscopic Analysis of Deterioration Indices of Soybeans for Process Control in Oil Milling Plant. J. Am. Oil Chem Soc. 71(10), 1049-1055.

Sohn, M., Himmelsbach, D., Morrison, W., Akin, De., Barton, Fe. (2006). Partial Least Squares Regression Calibration for Determining Wax Content in Processed Flax Fiber by Near-Infrared Spectroscopy. Society for Applied Spectroscopy. 60: 437-440.

Williams, P. (2001). Near-infrared technology: In the agricultural and food industries. In P. Williams, \& K. Norris (Eds.), (2nd ed.). American Association of Cereal Chemists. (pp. 296)St. Paul, Minn., USA: American Association of Cereal Chemists.

Yildirim,M., Bayram,I. (2019). The creation of the FT-NIR calibration for the determination of the amount of corn grain in concentrated feed. International Journal of Scientific and Technological Research. 5(8),73-79.

Zhou, X., Yang, Z., Huang, G., Han, L. (2012). Non-invasive detection of protein content in corn distillers dried grains with solubles: Method for selecting spectral variables to construct highperformance calibration model using near infrared reflectance spectroscopy. Journal of Near Infrared Spectroscopy, 20(3), 407.

Zhu, D., Wang, K., Zhang, D., Huang, W., Yang, G., Ma, Z., Wang, C. (2011). Quality assessment of crop seeds by near-infrared hyperspectral imaging. Sensor Letters, 9, 1144-1150. https://doi.org/10.1166/sl.2011.1377 